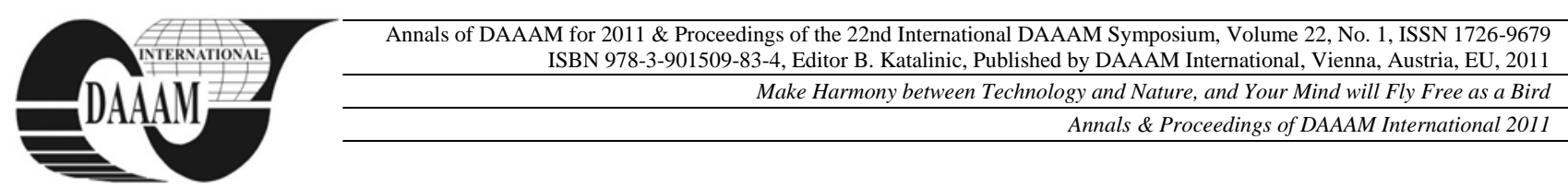

\title{
STRATEGIC AND TACTICAL MOVEMENTS AND ORGANIZATIONS' COMPETITIVENESS
}

\author{
RADU, C[atalina] \& POPESCU, D[oina]
}

\begin{abstract}
Organizations' competitiveness is a complex concept that should be analyzed in a continuous dynamics, as it is both an effect of current strategic and tactical movements and a cause of future performance. This paper aims to highlight the impact of organizations' current strategic and tactical movements on future organizational performance. The study is based on the results of a bigger project in which the authors were involved for analyzing organizations' competitiveness.

Key words: competition, competitiveness, strategic and tactical movements, dynamics
\end{abstract}

\section{INTRODUCTION}

Competitiveness is a complex concept that is widely debated by economists, managers, politicians, academicians, etc. worldwide, as there is a clear relationship between the organizations' competitiveness and elements such as durable development or standard of living. Although the definition of competitiveness seems to be very simple, the term is often used in situations in which it may have more than one sense or it is even misunderstood. The main cause for this is the high number of variables that affect organizations' competitiveness. Competitiveness is a controversial issue that requires continuous investigations of the involved variables' dynamics.

In this paper we will explore the area of assessing competitiveness in dynamics, as we consider any organization is interested not only in very good present result, but also in maintaining them over the time. The big number of factors affecting the environment's evolution, their complexity, the difficulty and even the impossibility of measuring such influences, the very big importance of chance in certain situations make difficult the inclusion of all the aspects in theoretical models of analysis with a high degree of accuracy; the dynamical aspect accentuates this problem. Organization is an open system that must adapt to continuous changes in the environment (and, why not, to turn some of the environmental elements into its favor).

\section{LITERATURE REVIEW}

Organizations face many issues, but two of them have a stronger impact: (1) how to grow a business and (2) how to ensure that the growth helps the organization become sustainable over time (Rieley, 2006). All businesses employ a particular business model, which reflects the management's hypothesis with respect to what customers want, how they want it, what they will pay and what an organization can do to best meet their customers' needs (Teece, 2010).

It is very important to understand that organizations having a good yet not perfect business model template are more likely to succeed if they are able to learn and adjust (Shirky, 2008).

We define competitiveness as the capability to successfully compete, to provide products and services as or more effectively and efficiently than relevant competitors for a specific time frame (Radu, 2009).
In order to have a good vision regarding a company's future, a careful analysis of the whole system a company is part of and the ability of the company to achieve future growth are clearly necessary (Woodhead and McCuish, 2003). The present competitive environment means more information sources, rapidly changing technologies, new management practices, more competences and shorter life cycles, therefore organizational change is increasingly important (Tseng, 2009).

Transformation process deserves a special attention, as, if carried without care, it will negatively influence the organization's level of competitiveness.

According to some authors (Bjelland and Chapman Wood, 2008), there are five distinct, reproducible ways of radically altering organizations: the standard model process ("holism"), transformation through the ambidextrous form, transformation through acquisition/restructuring, the Collins "Good-to-great" process, and improvisational transformation process. And there are also the hybrid approaches, which are mixtures between them. Of course, we should not necessarily look for radical changes, although they are quite often required in order to have a significant improvement in the level of competitiveness.

\section{CONCEPTUAL FRAMEWORK}

Competitiveness is a controversial issue that requires continuous investigations that consider the permanent dynamics of the involved variables. The main idea of our model is that future level of competitiveness is a result variable that depends on a series of cause variables: current level of competitiveness, current actions of the analyzed organization (strategic and tactical movements) as well as current actions of organization's main competitors, leadership development, organization's current competences and potential of competitiveness and all the external environment. Future level of competitiveness is the result of a transformation process that takes place depending on all the above mentioned factors (Radu, Grigore and Cătăneţ, 2009). Briefly, this model can be seen in Figure 1 on the following page.

Through the interaction between themselves and through their interaction with the environment, the organization's current actions and those of their competitors influence the future level of competitiveness.

In order to evaluate an organization's current actions, our inspiration came from the chess game (in the game of chess there are only two "competitors", but the idea can be extended to any other strategy game, where the number of players may significantly increase) (Radu, 2009). Although the chess game is substantially different from a project, the analogy can be made by using the triangle cost-time-quality.

- Cost: A player will not be able to win unless he/she pays constant attention to the cost of his/her actions. In chess, it is important not to lose pieces at a higher rate than the other player does (except for strategic movements). Extending to organizations, attention to the cost of actions means a better use of resources, outsourcing of non-core activities and use of strategic partners; 
- Time: Chess players have to rapidly react to competitors' movements, they have to constructively dispose of their time. What we particularly analyzed for the responding organizations was their flexibility;

- Quality: It is not enough for a player to rapidly move (time) and to act in order not to lose pieces (cost), if he/she underestimates the final objective of the game: checkmate. Extending to organizations it is also very important not to underestimate the goal and therefore the focus on customer.

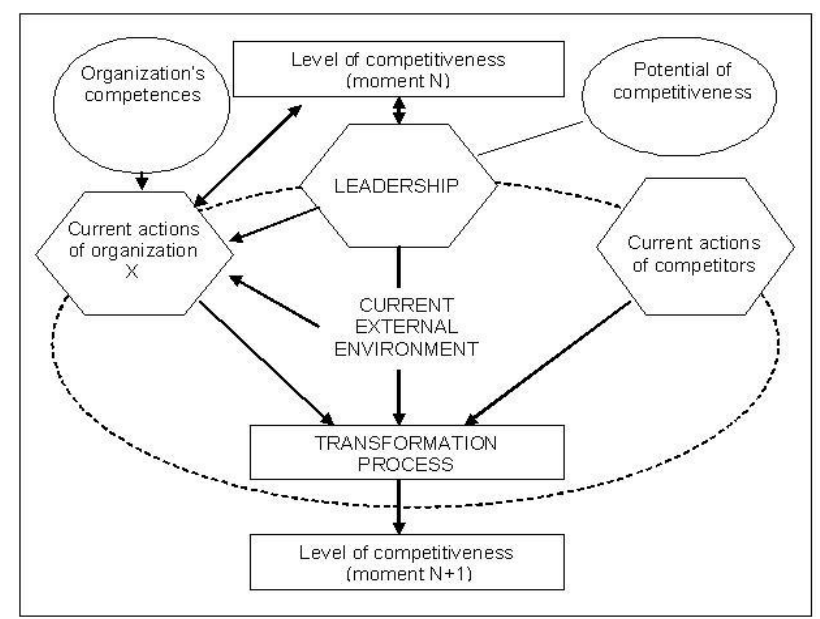

Fig. 1. Organization's dynamic competitiveness

For the purpose of this paper we are mainly interested in testing two hypotheses: (1) Organization's current actions (strategic and tactical movements) have a direct and positive influence on their future level of competitiveness; and (2) Competitors' current actions have a direct and negative influence on organization's future level of competitiveness.

\section{METHODOLOGY}

In order to test all our hypotheses, we had a bigger project in which we developed a questionnaire of 54 questions that was applied in two periods (June - September 2007 and June September 2009), in order to see the causal relationships and the transformations over time. 223 questionnaires were distributed to managers of different Romanian organizations (7 non-profit organizations, the rest of them companies of different scales and representing different fields of activity). Our final analysis was limited to 98 organizations.

\section{HYPOTHESES TESTING}

The graph that shows the dependency relationship between organizations' strategic and tactical movements and their future level of competitiveness is presented below (scores from 1 to 10):

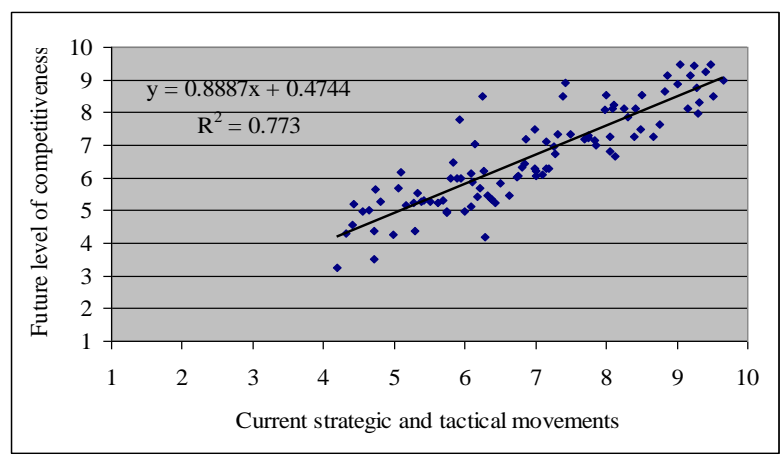

Fig. 2. Regression line - Strategic and tactical movements and organizations' competitiveness
The coefficient of determination $\mathrm{R}^{2}$ has a high value (0.7403). Linear relationship of dependence between the two variables is strong, as it can be seen from the figure, as there are quite few distant points (outliers). $F$ test and $p$ value show that the model is valid:

\begin{tabular}{|l|l|}
\hline Regression line: & $\mathrm{y}=0.8887 \cdot \mathrm{x}+0.4744$ \\
\hline Coefficient of determination $\left(\mathrm{R}^{2}\right):$ & 0.7730 \\
\hline Standard error: & 0.72 \\
\hline F test (Fisher): & 326.9442 \\
\hline $\mathrm{p}$-value: & $1.13 \cdot 10^{-32}$ \\
\hline
\end{tabular}

Tab. 1. Information regarding the regression line

Of course, the influence of competitors' strategic and tactical movements on a particular organization's competitiveness (the single negative relationship in the model) cannot be proved by using a questionnaire. However, this relationship is sustained by many real examples and can also be demonstrated by thinking a little differently. As we have already validated the hypothesis that a particular organization's strategic and tactical movements have a positive effect on their level of competitiveness, it is clear that correct actions will lead to their increased competitiveness, which is synonymous to lower competitors' levels of competitiveness. In other words, positive actions of A will lead to a lower competitiveness level of $\mathrm{B}$, which we had to demonstrate.

\section{CONCLUSIONS}

We can validate our hypotheses. Indeed, organization's current actions (strategic and tactical movements) have a direct and positive influence on their future level of competitiveness, and competitors' current actions have a direct and negative influence on organization's future level of competitiveness

\section{ACKNOWLEDGEMENTS}

This work was co-financed from the European Social Fund through Sectoral Operational Programme Human Resources Development 2007-2013, project no. POSDRU/1.5/S/59184 "Performance and excellence in postdoctoral research in Romanian economics science domain".

\section{REFERENCES}

Bjelland, ; Chapman Wood, R. (2008). Five ways to transform a business. Strategy \& Leadership, Chicago, Vol. 36, No. 3 , pp. $4-14$

Radu, C. (2009). Modalităţi de creştere a competitivităţii organizaţiilor in contextul exigenţelor actuale ale mediului concurenţial, $\mathrm{PhD}$ thesis, Academy of Economic Studies, Bucharest

Radu, C., Grigore, A.M. \& Cătăneţ, A. (2009). An integrative competitiveness model, Proceedings of the 4th International Conference on Business Excellence, Vol. 2, pp. $153-156$

Rieley, J.B. (2006). Strategy and Performance, The Telegraph Business Club, United Kingdom

Shirky, C. (2008). Here Comes Everybody: The Power of Organizing Without Organizations, Penguin, New York

Teece, D. (2010). Business Models, Business Strategy and Innovation, Long Range Planning, Vol. 43, pp. 172-194

Tseng, S.M. (2009). A study on customer, supplier and competitor knowledge using the knowledge chain model, International Journal of Information Management, Vol. 29, No. 1, pp. 488-496

Woodhead, R. \& McCuish, J. (2003). Achieving results: how to create value, Thomas Telford, London 